\title{
Best proximity point results in partially ordered metric spaces via simulation functions
}

\section{Bessem Samet}

\section{"Correspondence:}

bsamet@ksu.edu.sa

Department of Mathematics,

College of Science, King Saud

University, P.O. Box 2455, Riyadh,

11451, Saudi Arabia

\begin{abstract}
We obtain sufficient conditions for the existence and uniqueness of best proximity points for a new class of non-self mappings involving simulation functions in a metric space endowed with a partial order. Some interesting consequences including fixed point results via simulation functions are presented.
\end{abstract}

MSC: 90C26; 47H10;06A06

Keywords: best proximity point; fixed point; simulation function

\section{Introduction}

Recently, in [1] the authors introduced the class of simulation functions as follows.

Definition 1.1 We say that $\xi:[0, \infty) \times[0, \infty) \rightarrow \mathbb{R}$ is a simulation function if it satisfies the following conditions:

(i) $\xi(0,0)=0$;

(ii) $\xi(t, s)<s-t$, for every $t, s>0$;

(iii) if $\left\{a_{n}\right\}$ and $\left\{b_{n}\right\}$ are two sequences in $(0, \infty)$, then

$$
\lim _{n \rightarrow \infty} a_{n}=\lim _{n \rightarrow \infty} b_{n}>0 \Longrightarrow \limsup _{n \rightarrow \infty} \xi\left(a_{n}, b_{n}\right)<0 .
$$

Various examples of simulation functions were presented in [1]. The class of such functions will be denoted by $\mathcal{Z}$.

Definition 1.2 ([1]) Let $T: X \rightarrow X$ be a given operator, where $X$ is a nonempty set equipped with a metric $d$. We say that $T$ is a $\mathcal{Z}$-contraction with respect to $\xi \in \mathcal{Z}$ if

$$
\xi(d(T x, T y), d(x, y)) \geq 0, \quad \text { for all } x, y \in X .
$$

In [1], the authors established the following fixed point theorem that generalizes many previous results from the literature including the Banach fixed point theorem.

Theorem 1.3 ([1]) Let $T: X \rightarrow X$ be a given map, where $X$ is a nonempty set equipped with a metric $d$ such that $(X, d)$ is complete. Suppose that $T$ is a $\mathcal{Z}$-contraction with respect

(c) 2015 Samet. This article is distributed under the terms of the Creative Commons Attribution 4.0 International License (http://creativecommons.org/licenses/by/4.0/), which permits unrestricted use, distribution, and reproduction in any medium, provided you give appropriate credit to the original author(s) and the source, provide a link to the Creative Commons license, and indicate if changes were made. 
to $\xi \in \mathcal{Z}$. Then $T$ has a unique fixed point. Moreover, for any $x \in X$, the sequence $\left\{T^{n} x\right\}$ converges to this fixed point.

For other results via simulation functions, we refer to [2-7].

Let $(X, d)$ be a metric space. Consider a mapping $T: A \rightarrow B$, where $A$ and $B$ are nonempty subsets of $X$. If $d(x, T x)>0$ for every $x \in A$, then the set of fixed points of $T$ is empty. In this case, we are interested in finding a point $x \in A$ such that $d(x, T x)$ is minimum in some sense.

Definition 1.4 We say that $z \in A$ is a best proximity point of $T$ if

$$
d(z, T z)=d(A, B):=\inf \{d(x, y): x \in A, y \in B\} .
$$

Observe that if $d(A, B)=0$, then a best proximity point of $T$ is a fixed point of $T$.

The study of the existence of best proximity points is an interesting field of optimization and it attracted recently the attention of several researchers (see $[1,8-23]$ and the references therein).

In the sequel, we will use the following notations. Set

$$
A_{0}=\{x \in A: d(x, y)=d(A, B) \text {, for some } y \in B\}
$$

and

$$
B_{0}=\{y \in B: d(x, y)=d(A, B) \text {, for some } x \in A\} .
$$

We refer to [19] for sufficient conditions that guarantee that $A_{0}$ and $B_{0}$ are nonempty.

Now, we endow the set $X$ with a partial order $\preceq$. Let us introduce the following class of mappings. For a given simulation function $\xi \in \mathcal{Z}$, we denote by $\mathcal{T}_{\xi}$ the set of mappings $T: A \rightarrow B$ satisfying the following conditions:

(C1) for every $x_{1}, x_{2}, y_{1}, y_{2} \in A$, we have

$$
y_{1} \preceq y_{2}, \quad d\left(x_{1}, T y_{1}\right)=d\left(x_{2}, T y_{2}\right)=d(A, B) \quad \Longrightarrow \quad x_{1} \preceq x_{2} ;
$$

(C2) for every $x, y, u_{1}, u_{2} \in A$, we have

$$
x \preceq y, x \neq y, \quad d\left(u_{1}, T x\right)=d\left(u_{2}, T y\right)=d(A, B) \quad \Longrightarrow \quad \xi\left(d\left(u_{1}, u_{2}\right), m(x, y)\right) \geq 0,
$$

where

$$
m(x, y)=\max \left\{\frac{d\left(x, u_{1}\right) d\left(y, u_{2}\right)}{d(x, y)}, d(x, y)\right\} .
$$

Our aim in this paper is to study the existence and uniqueness of best proximity points for non-self mappings $T: A \rightarrow B$ that belong to the class $\mathcal{T}_{\xi}$, for some simulation function $\xi \in \mathcal{Z}$.

\section{Main results}

Our first main result is the following. 
Theorem 2.1 Let $T \in \mathcal{T}_{\xi}$, for some $\xi \in \mathcal{Z}$. Suppose that the following conditions hold:

(1) $(X, d)$ is complete;

(2) $A$ is closed with respect to the metric d;

(3) $T\left(A_{0}\right) \subseteq B_{0}$;

(4) there exist $x_{0}, x_{1} \in A_{0}$ such that

$$
d\left(x_{1}, T x_{0}\right)=d(A, B), \quad x_{0} \preceq x_{1}
$$

(5) $T$ is continuous.

Then $T$ has a best proximity point, that is, there is some $z \in A$ such that $d(z, T z)=d(A, B)$.

Proof By condition (4), we have

$$
d\left(x_{1}, T x_{0}\right)=d(A, B)
$$

for some $x_{0}, x_{1} \in A_{0}$ such that $x_{0} \preceq x_{1}$. Condition (3) implies that $T x_{1} \in B_{0}$, which yields

$$
d\left(x_{2}, T x_{1}\right)=d(A, B)
$$

for some $x_{2} \in A_{0}$. Since $x_{0} \preceq x_{1}$, condition (C1) implies that $x_{1} \preceq x_{2}$. Continuing this process, by induction, we can construct a sequence $\left\{x_{n}\right\} \subset A_{0}$ such that

$$
d\left(x_{n+1}, T x_{n}\right)=d(A, B), \quad n=0,1,2, \ldots
$$

and

$$
x_{0} \preceq x_{1} \preceq x_{2} \preceq \cdots \preceq x_{n} \preceq x_{n+1} \preceq \cdots .
$$

Suppose that for some $p=0,1,2, \ldots$, we have $x_{p+1}=x_{p}$. In this case, we get $d\left(x_{p}, T x_{p}\right)=$ $d(A, B)$, that is, $x_{p}$ is a best proximity point of $T$. So, without restriction of the generality, we may suppose that

$$
x_{n} \neq x_{n+1}, \quad n=0,1,2, \ldots
$$

Since

$$
x_{n} \preceq x_{n+1}, x_{n} \neq x_{n+1}, \quad d\left(x_{n}, T x_{n-1}\right)=d\left(x_{n+1}, T x_{n}\right)=d(A, B), \quad n=1,2,3, \ldots,
$$

it follows from condition (C2) that

$$
\xi\left(d\left(x_{n}, x_{n+1}\right), m\left(x_{n-1}, x_{n}\right)\right) \geq 0, \quad n=1,2,3, \ldots
$$

where

$$
\begin{aligned}
m\left(x_{n-1}, x_{n}\right) & =\max \left\{\frac{d\left(x_{n-1}, x_{n}\right) d\left(x_{n}, x_{n+1}\right)}{d\left(x_{n-1}, x_{n}\right)}, d\left(x_{n-1}, x_{n}\right)\right\} \\
& =\max \left\{d\left(x_{n}, x_{n+1}\right), d\left(x_{n-1}, x_{n}\right)\right\} .
\end{aligned}
$$


Suppose that for some $n_{0}=1,2,3, \ldots$, we have

$$
\max \left\{d\left(x_{n_{0}}, x_{n_{0}+1}\right), d\left(x_{n_{0}-1}, x_{n_{0}}\right)\right\}=d\left(x_{n_{0}}, x_{n_{0}+1}\right) .
$$

In this case, we obtain

$$
0 \leq \xi\left(d\left(x_{n_{0}}, x_{n_{0}+1}\right), d\left(x_{n_{0}}, x_{n_{0}+1}\right)\right)
$$

On the other hand, since $d\left(x_{n_{0}}, x_{n_{0}+1}\right)>0$, using the property (ii) of a simulation function, we obtain

$$
\xi\left(d\left(x_{n_{0}}, x_{n_{0}+1}\right), d\left(x_{n_{0}}, x_{n_{0}+1}\right)\right)<0,
$$

which is a contradiction. As a consequence,

$$
\max \left\{d\left(x_{n}, x_{n+1}\right), d\left(x_{n-1}, x_{n}\right)\right\}=d\left(x_{n-1}, x_{n}\right), \quad n=1,2,3, \ldots
$$

Thus, we obtain

$$
\xi\left(d\left(x_{n}, x_{n+1}\right), d\left(x_{n-1}, x_{n}\right)\right) \geq 0, \quad n=1,2,3, \ldots
$$

From (2.2), we deduce that the sequence $\left\{r_{n}\right\}$ defined by

$$
r_{n}=d\left(x_{n}, x_{n+1}\right), \quad n=0,1,2, \ldots
$$

is decreasing, which yields

$$
\lim _{n \rightarrow \infty} r_{n}=r,
$$

where $r \in[0, \infty)$. Suppose that $r>0$. Using (2.3) and the property (iii) of a simulation function, we deduce that

$$
0 \leq \limsup _{n \rightarrow \infty} \xi\left(d\left(x_{n}, x_{n+1}\right), d\left(x_{n-1}, x_{n}\right)\right)<0,
$$

which is a contradiction. As consequence, we have

$$
\lim _{n \rightarrow \infty} d\left(x_{n}, x_{n+1}\right)=0
$$

Let us prove now that $\left\{x_{n}\right\}$ is a Cauchy sequence. We argue by contradiction by supposing that $\left\{x_{n}\right\}$ is not a Cauchy sequence. In this case, there is some $\varepsilon>0$ for which there are subsequences $\left\{x_{m(k)}\right\}$ and $\left\{x_{n(k)}\right\}$ of $\left\{x_{n}\right\}$ such that

$$
n(k)>m(k)>k, \quad d\left(x_{m(k)}, x_{n(k)}\right) \geq \varepsilon, \quad d\left(x_{m(k)}, x_{n(k)-1}\right)<\varepsilon .
$$

Using the triangle inequality, we have

$$
\varepsilon \leq d\left(x_{m(k)}, x_{n(k)}\right) \leq d\left(x_{m(k)}, x_{n(k)-1}\right)+d\left(x_{n(k)-1}, x_{n(k)}\right)<\varepsilon+d\left(x_{n(k)-1}, x_{n(k)}\right) .
$$


Thus we have

$$
\varepsilon \leq d\left(x_{m(k)}, x_{n(k)}\right)<\varepsilon+d\left(x_{n(k)-1}, x_{n(k)}\right), \quad \text { for all } k .
$$

Letting $k \rightarrow \infty$ and using (2.4), we obtain

$$
\lim _{n \rightarrow \infty} d\left(x_{m(k)}, x_{n(k)}\right)=\varepsilon
$$

Again, the triangle inequality yields

$$
\left|d\left(x_{n(k)-1}, x_{m(k)}\right)-d\left(x_{m(k)}, x_{n(k)}\right)\right| \leq d\left(x_{n(k)-1}, x_{n(k)}\right), \quad \text { for all } k \text {. }
$$

Letting $k \rightarrow \infty$, using (2.4) and (2.5), we obtain

$$
\lim _{n \rightarrow \infty} d\left(x_{n(k)-1}, x_{m(k)}\right)=\varepsilon
$$

Similarly, we have

$$
\left|d\left(x_{n(k)-1}, x_{m(k)-1}\right)-d\left(x_{n(k)-1}, x_{m(k)}\right)\right| \leq d\left(x_{m(k)-1}, x_{m(k)}\right), \quad \text { for all } k \text {. }
$$

Letting $k \rightarrow \infty$, using (2.4) and (2.6), we obtain

$$
\lim _{n \rightarrow \infty} d\left(x_{n(k)-1}, x_{m(k)-1}\right)=\varepsilon
$$

Observe that for $k$ large enough, we have

$$
x_{m(k)-1} \preceq x_{n(k)-1}, \quad x_{m(k)-1} \neq x_{n(k)-1}
$$

and

$$
d\left(x_{m(k)}, T x_{m(k)-1}\right)=d\left(x_{n(k)}, T x_{n(k)-1}\right)=d(A, B) .
$$

Then condition ( $\mathrm{C} 2$ ) yields

$$
\xi\left(d\left(x_{m(k)}, x_{n(k)}\right), m\left(x_{m(k)-1}, x_{n(k)-1}\right)\right) \geq 0, \quad \text { for all } k \text {. }
$$

On the other hand, for all $k$, we have

$$
m\left(x_{m(k)-1}, x_{n(k)-1}\right)=\max \left\{\frac{d\left(x_{m(k)-1}, x_{m(k)}\right) d\left(x_{n(k)-1}, x_{n(k)}\right)}{d\left(x_{m(k)-1}, x_{n(k)-1}\right)}, d\left(x_{m(k)-1}, x_{n(k)-1}\right)\right\} .
$$

Passing $k \rightarrow \infty$ and using (2.4) and (2.7), we get

$$
\lim _{k \rightarrow \infty} m\left(x_{m(k)-1}, x_{n(k)-1}\right)=\varepsilon .
$$

Using (2.5), (2.9), (2.8) and the condition (iii) of a simulation function, we have

$$
0 \leq \limsup _{k \rightarrow \infty} \xi\left(d\left(x_{m(k)}, x_{n(k)}\right), m\left(x_{m(k)-1}, x_{n(k)-1}\right)\right)<0,
$$


which is a contradiction. As consequence, the sequence $\left\{x_{n}\right\}$ is Cauchy. Since $A$ is a closed subset of the complete metric space $(X, d)$ (from conditions (1) and (2)), there is some $z \in A$ such that

$$
\lim _{n \rightarrow \infty} d\left(x_{n}, z\right)=0
$$

The continuity of $T$ (from condition (5)) yields

$$
\lim _{n \rightarrow \infty} d\left(T x_{n}, T z\right)=0
$$

Since $d\left(x_{n+1}, T x_{n}\right)=d(A, B)$ for all $n=0,1,2, \ldots$, we obtain

$$
d(A, B)=\lim _{n \rightarrow \infty} d\left(x_{n+1}, T x_{n}\right)=d(z, T z)
$$

that is, $z \in A$ is a best proximity point of $T$. This ends the proof.

Next, we obtain a best proximity point result for mappings $T \in \mathcal{T}_{\xi}$ that are not necessarily continuous.

We say that the set $A$ is $(d, \preceq)$-regular if it satisfies the following property:

$$
\left\{a_{n}\right\} \subset A \text { is nondecreasing w.r.t. } \preceq \text { and } \lim _{n \rightarrow \infty} d\left(a_{n}, a\right)=0 \quad \Longrightarrow \quad a=\sup \left\{a_{n}\right\} .
$$

Theorem 2.2 Let $T \in \mathcal{T}_{\xi}$, for some $\xi \in \mathcal{Z}$. Suppose that the following conditions hold:

(1) $(X, d)$ is complete;

(2) $A_{0}$ is closed;

(3) $T\left(A_{0}\right) \subseteq B_{0}$;

(4) there exist $x_{0}, x_{1} \in A_{0}$ such that

$$
d\left(x_{1}, T x_{0}\right)=d(A, B), \quad x_{0} \preceq x_{1}
$$

(5) $A$ is $(d, \preceq)$-regular.

Then $T$ has a best proximity point, that is, there is some $z \in A$ such that $d(z, T z)=d(A, B)$.

Proof Let us consider the sequence $\left\{x_{n}\right\} \subset A_{0}$ defined by (2.1). Following the proof of Theorem 2.1, we know that $\left\{x_{n}\right\}$ is a Cauchy sequence. Since $A_{0}$ is closed, there is some $z \in A_{0}$ such that

$$
\lim _{n \rightarrow \infty} d\left(x_{n}, z\right)=0
$$

From condition (3), we have $T z \in B_{0}$, which yields

$$
d\left(y_{1}, T z\right)=d(A, B)
$$

for some $y_{1} \in A_{0}$. On the other hand, the regularity condition (5) implies that

$$
x_{n} \preceq z, \quad \text { for all } n \text {. }
$$


Since for all $n$,

$$
x_{n} \preceq z, \quad d\left(x_{n+1}, T x_{n}\right)=d\left(y_{1}, T z\right)=d(A, B),
$$

condition $(\mathrm{C} 1)$ yields

$$
x_{n+1} \preceq y_{1}, \quad \text { for all } n \text {. }
$$

On the other hand, we know that $z=\sup \left\{x_{n}\right\}$, which implies that

$$
z \preceq y_{1} .
$$

Thus we have

$$
d\left(y_{1}, T z\right)=d(A, B), \quad z \preceq y_{1} .
$$

Again, since $T y_{1} \in B_{0}$, there is some $y_{2} \in A_{0}$ such that $d\left(y_{2}, T y_{1}\right)=d(A, B)$. Condition (C1) yields $y_{1} \preceq y_{2}$. Thus we have

$$
d\left(y_{2}, T y_{1}\right)=d(A, B), \quad y_{1} \preceq y_{2} .
$$

Set $y_{0}=z$ and continuing this process, we can build a sequence $\left\{y_{n}\right\} \subset A_{0}$ such that

$$
d\left(y_{n+1}, T y_{n}\right)=d(A, B), \quad n=0,1,2, \ldots
$$

and

$$
y_{0} \preceq y_{1} \preceq y_{2} \preceq \cdots \preceq y_{n} \preceq y_{n+1} \preceq \cdots .
$$

Following similar arguments as in the proof of Theorem 2.1, we can prove that $\left\{y_{n}\right\}$ is a Cauchy sequence in the closed subset $A_{0}$ of the complete metric space $(X, d)$, which yields

$$
\lim _{n \rightarrow \infty} d\left(y_{n}, y\right)=0
$$

for some $y \in A_{0}$. The regularity assumption (5) implies that $y=\sup \left\{y_{n}\right\}$. So, we have

$$
x_{n} \preceq z=y_{0} \preceq y_{1} \preceq \cdots \preceq y_{n} \preceq y, \quad \text { for all } n \text {. }
$$

We claim that $z=y$. In order to prove our claim, suppose that $d(z, y)>0$. Set

$$
I=\left\{n: x_{n}=z\right\} .
$$

We consider two cases.

Case 1. If $|I|=\infty$.

In this case, there is a subsequence $\left\{x_{n_{k}}\right\}$ of $\left\{x_{n}\right\}$ such that

$$
x_{n_{k}}=z, \quad \text { for all } k \text {, }
$$

which implies that $z$ is a best proximity point. So, this case is trivial. 
Case 2. If $|I|<\infty$.

In this case, for $n$ large enough, we have

$$
x_{n} \neq z, \quad x_{n} \preceq z \preceq y_{n}, \quad \text { for all } n .
$$

From condition (C2), for $n$ large enough, we obtain

$$
\xi\left(d\left(x_{n+1}, y_{n+1}\right), m\left(x_{n}, y_{n}\right)\right) \geq 0,
$$

where

$$
m\left(x_{n}, y_{n}\right)=\max \left\{\frac{d\left(x_{n}, x_{n+1}\right) d\left(y_{n}, y_{n+1}\right)}{d\left(x_{n}, y_{n}\right)}, d\left(x_{n}, y_{n}\right)\right\}
$$

Observe that

$$
\lim _{n \rightarrow \infty} d\left(x_{n+1}, y_{n+1}\right)=\lim _{n \rightarrow \infty} m\left(x_{n}, y_{n}\right)=d(z, y)>0
$$

From the property (iii) of simulation functions, we obtain

$$
0 \leq \limsup _{n \rightarrow \infty} \xi\left(d\left(x_{n+1}, y_{n+1}\right), m\left(x_{n}, y_{n}\right)\right)<0,
$$

which is a contradiction. As consequence, we have $z=y$.

Since $z=y$, we obtain

$$
x_{n} \preceq z=y_{0} \preceq y_{1} \preceq \cdots \preceq y_{n} \preceq y=z, \quad \text { for all } n,
$$

which implies that

$$
y_{n}=z, \quad \text { for all } n \text {. }
$$

Since $d\left(y_{n+1}, T y_{n}\right)=d(A, B)$, we have $d(z, T z)=d(A, b)$, that is, $z$ is a best proximity point of $T$. This completes the proof.

Note that the assumptions in Theorems 2.1 and 2.2 do not guarantee the uniqueness of the best proximity point. The next example shows this fact.

Example 2.3 Let $X$ be the subset of $\mathbb{R}^{3}$ given by

$$
X=\{(0,0,1),(1,0,0),(0,0,-1),(-1,0,0)\} .
$$

We endow $X$ with the partial order $\preceq$ defined by

$$
(x, y, z) \preceq\left(x^{\prime}, y^{\prime}, z^{\prime}\right) \quad \Longleftrightarrow \quad x \leq x^{\prime}, y \leq y^{\prime}, z \leq z^{\prime}
$$

Let $d$ be the Euclidean metric on $\mathbb{R}^{3}$. Then $(X, d)$ is a complete metric space. Set

$$
A=\{(0,0,1),(1,0,0)\} \quad \text { and } \quad B=\{(0,0,-1),(-1,0,0)\} .
$$


In this case, we have

$$
d(A, B)=\sqrt{2}, \quad A_{0}=A, \quad B_{0}=B .
$$

Let $T: A \rightarrow B$ be the mapping defined by

$$
T(x, y, z)=(-z,-y,-x), \quad(x, y, z) \in A .
$$

Then $T$ is continuous and $T \in \mathcal{T}_{\xi}$ for every $\xi \in \mathcal{Z}$. Moreover, it can be shown that all the other conditions of Theorems 2.1 and 2.2 are satisfied. However, $z_{1}=(0,0,1)$ and $z_{2}=(1,0,0)$ are two best proximity points of $T$.

In the next theorem, we give a sufficient condition for the uniqueness of the best proximity point.

Theorem 2.4 In addition to the assumptions of Theorem 2.1 (resp. Theorem 2.2), suppose that

$$
\text { for every }(x, y) \in A_{0} \times A_{0} \text {, there is some } w \in A_{0} \text { such that } x \preceq w, y \preceq w \text {. }
$$

Then $T$ has a unique best proximity point.

Proof From Theorem 2.1 (resp. Theorem 2.2), the set of best proximity points of $T$ is not empty. Suppose that $z_{1}, z_{2} \in A_{0}$ are two distinct best proximity points of $T$, that is,

$$
d\left(z_{1}, T z_{1}\right)=d\left(z_{2}, T z_{2}\right)=d(A, B), \quad d\left(z_{1}, z_{2}\right)>0 .
$$

We consider two cases.

Case 1. If $z_{1}$ and $z_{2}$ are comparable.

We may assume that $z_{1} \preceq z_{2}$. From condition (C2), we have

$$
\xi\left(d\left(z_{1}, z_{2}\right), m\left(z_{1}, z_{2}\right)\right) \geq 0,
$$

where

$$
m\left(z_{1}, z_{2}\right)=\max \left\{\frac{d\left(z_{1}, z_{1}\right) d\left(z_{2}, z_{2}\right)}{d\left(z_{1}, z_{2}\right)}, d\left(z_{1}, z_{2}\right)\right\}=d\left(z_{1}, z_{2}\right) .
$$

Thus we have

$$
\xi\left(d\left(z_{1}, z_{2}\right), d\left(z_{1}, z_{2}\right)\right) \geq 0
$$

which is a contradiction with the property (ii) of a simulation function.

Case 2. If $z_{1}$ and $z_{2}$ are not comparable.

In this case, there is some $w \in A_{0}$ such that

$$
z_{1} \preceq w, \quad z_{2} \preceq w, \quad w \notin\left\{z_{1}, z_{2}\right\} .
$$


Since $T\left(A_{0}\right) \subseteq B_{0}$, we can build a sequence $\left\{w_{n}\right\} \subset A_{0}$ such that

$$
d\left(w_{n+1}, T w_{n}\right)=d(A, B), \quad n=0,1,2, \ldots
$$

with $w_{0}=w$. From condition $(\mathrm{C} 1)$, we get

$$
z_{1} \preceq w_{n}, \quad n=0,1,2, \ldots
$$

If for some $k$, we have $z_{1}=w_{k}$, using condition (C1), we have $w_{k+1} \preceq z_{1}$, which yields $w_{k+1}=z_{1}$. Arguing similarly, we obtain $w_{n}=z_{1}$ for every $n \geq k$. Thus we have

$$
\lim _{n \rightarrow \infty} d\left(w_{n}, z_{1}\right)=0
$$

If $w_{n} \neq z_{1}$ for every $n$, from condition (C2), we have

$$
\xi\left(d\left(z_{1}, w_{n+1}\right), m\left(z_{1}, w_{n}\right)\right) \geq 0, \quad n=0,1,2, \ldots,
$$

where

$$
m\left(z_{1}, w_{n}\right)=\max \left\{\frac{d\left(z_{1}, z_{1}\right) d\left(w_{n}, w_{n+1}\right)}{d\left(z_{1}, w_{n}\right)}, d\left(z_{1}, w_{n}\right)\right\}=d\left(z_{1}, w_{n}\right) .
$$

Thus we have

$$
\xi\left(d\left(z_{1}, w_{n+1}\right), d\left(z_{1}, w_{n}\right)\right) \geq 0, \quad n=0,1,2, \ldots
$$

On the other hand, from the property (ii) of a simulation function, we have

$$
0 \leq \xi\left(d\left(z_{1}, w_{n+1}\right), d\left(z_{1}, w_{n}\right)\right)<d\left(z_{1}, w_{n}\right)-d\left(z_{1}, w_{n+1}\right), \quad n=0,1,2, \ldots
$$

We deduce that the sequence $\left\{s_{n}\right\}$ defined by

$$
s_{n}=d\left(z_{1}, w_{n}\right), \quad n=0,1,2, \ldots
$$

converges to some $s \geq 0$. But the property (ii) of a simulation function gives us that $s=0$.

Thus, in all cases, we have

$$
\lim _{n \rightarrow \infty} d\left(w_{n}, z_{1}\right)=0
$$

Analogously, we can prove that

$$
\lim _{n \rightarrow \infty} d\left(w_{n}, z_{2}\right)=0 .
$$

Finally, the uniqueness of the limit yields the desired result.

In the following corollaries we deduce some known and some new results in best proximity point theory via various choices of simulation functions.

We denote by $\mathcal{F}$ the set of mappings $T: A \rightarrow B$ satisfying the following conditions: 
(F1) for every $x_{1}, x_{2}, y_{1}, y_{2} \in A$, we have

$$
y_{1} \preceq y_{2}, \quad d\left(x_{1}, T y_{1}\right)=d\left(x_{2}, T y_{2}\right)=d(A, B) \quad \Longrightarrow \quad x_{1} \preceq x_{2}
$$

(F2) for every $x, y, u_{1}, u_{2} \in A$, we have

$$
\begin{aligned}
x & \preceq y, x \neq y, \quad d\left(u_{1}, T x\right)=d\left(u_{2}, T y\right)=d(A, B) \\
\Longrightarrow & d\left(u_{1}, u_{2}\right) \leq k \max \left\{\frac{d\left(x, u_{1}\right) d\left(y, u_{2}\right)}{d(x, y)}, d(x, y)\right\}
\end{aligned}
$$

for some constant $k \in(0,1)$.

Take $\xi(t, s)=k s-t$, for $t, s \geq 0$, we deduce from Theorems 2.1, 2.2 and 2.4 the following results.

Corollary 2.5 Let $T \in \mathcal{F}$. Suppose that the following conditions hold:

(1) $(X, d)$ is complete;

(2) $A$ is closed with respect to the metric d;

(3) $T\left(A_{0}\right) \subseteq B_{0}$;

(4) there exist $x_{0}, x_{1} \in A_{0}$ such that

$$
d\left(x_{1}, T x_{0}\right)=d(A, B), \quad x_{0} \preceq x_{1}
$$

(5) $T$ is continuous.

Then $T$ has a best proximity point, that is, there is some $z \in A$ such that $d(z, T z)=d(A, B)$.

Corollary 2.6 Let $T \in \mathcal{F}$. Suppose that the following conditions hold:

(1) $(X, d)$ is complete;

(2) $A_{0}$ is closed;

(3) $T\left(A_{0}\right) \subseteq B_{0}$;

(4) there exist $x_{0}, x_{1} \in A_{0}$ such that

$$
d\left(x_{1}, T x_{0}\right)=d(A, B), \quad x_{0} \preceq x_{1}
$$

(5) $A$ is $(d, \preceq)$-regular.

Then $T$ has a best proximity point, that is, there is some $z \in A$ such that $d(z, T z)=d(A, B)$.

Corollary 2.7 In addition to the assumptions of Corollary 2.5 (resp. Corollary 2.6), suppose that

for every $(x, y) \in A_{0} \times A_{0}$, there is some $w \in A_{0}$ such that $x \preceq w, y \preceq w$.

Then T has a unique best proximity point.

We denote by $\mathcal{G}$ the set of mappings $T: A \rightarrow B$ satisfying the following conditions:

(G1) for every $x_{1}, x_{2}, y_{1}, y_{2} \in A$, we have

$$
y_{1} \preceq y_{2}, \quad d\left(x_{1}, T y_{1}\right)=d\left(x_{2}, T y_{2}\right)=d(A, B) \quad \Longrightarrow \quad x_{1} \preceq x_{2} ;
$$


(G2) for every $x, y, u_{1}, u_{2} \in A$, we have

$$
\begin{aligned}
x \preceq y, x \neq y, \quad d\left(u_{1}, T x\right) & d\left(u_{2}, T y\right)=d(A, B) \\
\Longrightarrow \quad d\left(u_{1}, u_{2}\right) \leq \max & \left\{\frac{d\left(x, u_{1}\right) d\left(y, u_{2}\right)}{d(x, y)}, d(x, y)\right\} \\
& -\varphi\left(\max \left\{\frac{d\left(x, u_{1}\right) d\left(y, u_{2}\right)}{d(x, y)}, d(x, y)\right\}\right),
\end{aligned}
$$

where $\varphi:[0, \infty) \rightarrow[0, \infty)$ is lower semi-continuous function and $\varphi^{-1}(\{0\})=\{0\}$.

Take $\xi(t, s)=s-\varphi(s)-t$, for $t, s \geq 0$, we deduce from Theorems 2.1, 2.2 and 2.4 the following results obtained in [23].

Corollary 2.8 Let $T \in \mathcal{G}$. Suppose that the following conditions hold:

(1) $(X, d)$ is complete;

(2) $A$ is closed with respect to the metric d;

(3) $T\left(A_{0}\right) \subseteq B_{0}$;

(4) there exist $x_{0}, x_{1} \in A_{0}$ such that

$$
d\left(x_{1}, T x_{0}\right)=d(A, B), \quad x_{0} \preceq x_{1} ;
$$

(5) $T$ is continuous

Then $T$ has a best proximity point, that is, there is some $z \in A$ such that $d(z, T z)=d(A, B)$.

Corollary 2.9 Let $T \in \mathcal{G}$. Suppose that the following conditions hold:

(1) $(X, d)$ is complete;

(2) $A_{0}$ is closed;

(3) $T\left(A_{0}\right) \subseteq B_{0}$;

(4) there exist $x_{0}, x_{1} \in A_{0}$ such that

$$
d\left(x_{1}, T x_{0}\right)=d(A, B), \quad x_{0} \preceq x_{1}
$$

(5) $A$ is $(d, \preceq)$-regular.

Then $T$ has a best proximity point, that is, there is some $z \in A$ such that $d(z, T z)=d(A, B)$.

Corollary 2.10 In addition to the assumptions of Corollary 2.8 (resp. Corollary 2.9), suppose that

$$
\text { for every }(x, y) \in A_{0} \times A_{0} \text {, there is some } w \in A_{0} \text { such that } x \preceq w, y \preceq w \text {. }
$$

Then $T$ has a unique best proximity point.

We denote by $\mathcal{H}$ the set of mappings $T: A \rightarrow B$ satisfying the following conditions:

(H1) for every $x_{1}, x_{2}, y_{1}, y_{2} \in A$, we have

$$
y_{1} \preceq y_{2}, \quad d\left(x_{1}, T y_{1}\right)=d\left(x_{2}, T y_{2}\right)=d(A, B) \quad \Longrightarrow \quad x_{1} \preceq x_{2} ;
$$


(H2) for every $x, y, u_{1}, u_{2} \in A$, we have

$$
\begin{aligned}
x \preceq y, x \neq y, \quad d\left(u_{1}, T x\right)=d\left(u_{2}, T y\right)=d(A, B) \\
\Longrightarrow d\left(u_{1}, u_{2}\right) \leq \varphi\left(\max \left\{\frac{d\left(x, u_{1}\right) d\left(y, u_{2}\right)}{d(x, y)}, d(x, y)\right\}\right) \\
\times \max \left\{\frac{d\left(x, u_{1}\right) d\left(y, u_{2}\right)}{d(x, y)}, d(x, y)\right\},
\end{aligned}
$$

where $\varphi:[0, \infty) \rightarrow[0,1)$ is a function such that $\limsup _{t \rightarrow r^{+}} \varphi(t)<1$, for all $r>0$.

Take $\xi(t, s)=s \varphi(s)-t$, for $t, s \geq 0$, we deduce from Theorems 2.1, 2.2 and 2.4 the following results.

Corollary 2.11 Let $T \in \mathcal{H}$. Suppose that the following conditions hold:

(1) $(X, d)$ is complete;

(2) $A$ is closed with respect to the metric d;

(3) $T\left(A_{0}\right) \subseteq B_{0}$;

(4) there exist $x_{0}, x_{1} \in A_{0}$ such that

$$
d\left(x_{1}, T x_{0}\right)=d(A, B), \quad x_{0} \preceq x_{1}
$$

(5) $T$ is continuous.

Then $T$ has a best proximity point, that is, there is some $z \in A$ such that $d(z, T z)=d(A, B)$.

Corollary 2.12 Let $T \in \mathcal{H}$. Suppose that the following conditions hold:

(1) $(X, d)$ is complete;

(2) $A_{0}$ is closed;

(3) $T\left(A_{0}\right) \subseteq B_{0}$;

(4) there exist $x_{0}, x_{1} \in A_{0}$ such that

$$
d\left(x_{1}, T x_{0}\right)=d(A, B), \quad x_{0} \preceq x_{1}
$$

(5) $A$ is $(d, \preceq)$-regular.

Then $T$ has a best proximity point, that is, there is some $z \in A$ such that $d(z, T z)=d(A, B)$.

Corollary 2.13 In addition to the assumptions of Corollary 2.11 (resp. Corollary 2.12), suppose that

$$
\text { for every }(x, y) \in A_{0} \times A_{0} \text {, there is some } w \in A_{0} \text { such that } x \preceq w, y \preceq w \text {. }
$$

Then $T$ has a unique best proximity point.

Finally, take $A=B=X$ in Theorems 2.1, 2.2 and 2.4, we obtain the following fixed point theorems.

For a given simulation function $\xi \in \mathcal{Z}$, we denote by $\mathcal{C}_{\xi}$ the class of mappings $T: X \rightarrow X$ satisfying the following conditions:

(I) for every $x, y \in X$, we have

$$
x \preceq y \quad \Longrightarrow \quad T x \preceq T y
$$


(II) for every $x, y \in X$, we have

$$
x \preceq y, x \neq y \quad \Longrightarrow \quad \xi\left(d(T x, T y), \max \left\{\frac{d(x, T x) d(y, T y)}{d(x, y)}, d(x, y)\right\}\right) \geq 0 .
$$

Corollary 2.14 Let $T \in \mathcal{C}_{\xi}$, for some $\xi \in \mathcal{Z}$. Suppose that

(1) $(X, d)$ is complete;

(2) there exists some $x_{0} \in X$ such that $x_{0} \preceq T x_{0}$;

(3) $T$ is continuous.

Then $T$ has a fixed point, that is, there is some $z \in X$ such that $z=T z$.

\section{Corollary 2.15 Let $T \in \mathcal{C}_{\xi}$, for some $\xi \in \mathcal{Z}$. Suppose that}

(1) $(X, d)$ is complete;

(2) there exists some $x_{0} \in X$ such that $x_{0} \preceq T x_{0}$;

(3) $X$ is $(d, \preceq)$-regular.

Then $T$ has a fixed point, that is, there is some $z \in X$ such that $z=T z$.

Corollary 2.16 In addition to the assumptions of Corollary 2.14 (resp. Corollary 2.15), suppose that

for every $(x, y) \in X \times X$, there is some $w \in X$ such that $x \preceq w, y \preceq w$.

\section{Then $T$ has a unique fixed point.}

\section{Competing interests}

The author declares that he has no competing interests.

\section{Acknowledgements}

The author extends his sincere appreciation to the Deanship of Scientific Research at King Saud University for its funding this Prolific Research group (PRG-1436-10).

Received: 10 August 2015 Accepted: 7 December 2015 Published online: 23 December 2015

\section{References}

1. Khojasteh, F, Shukla, S, Radenović, S: A new approach to the study of fixed point theory for simulation functions. Filomat 29(6), 1189-1194 (2015)

2. Argoubi, H, Samet, B, Vetro, C: Nonlinear contractions involving simulation functions in a metric space with a partial order. J. Nonlinear Sci. Appl. 8, 1082-1094 (2015)

3. Du, WS, Khojasteh, F: New results and generalizations for approximate fixed point property and their applications. Abstr. Appl. Anal. 2014, Article ID 581267 (2014)

4. Du, WS, Khojasteh, F, Chiu, YN: Some generalizations of Mizoguchi-Takahashi's fixed point theorem with new local constraints. Fixed Point Theory Appl. 2014, 31 (2014)

5. Khojasteh, F, Karapinar, E, Radenović, S: Metric space: a generalization. Math. Probl. Eng. 2013, Article ID 504609 (2013)

6. Roldán-López-de-Hierro, AF, Karapinar, E, Roldán-López-de-Hierro, C, Martínez-Moreno, J: Coincidence point theorems on metric spaces via simulation functions. J. Comput. Appl. Math. 275, 345-355 (2015)

7. Roldán-López-de-Hierro, AF, Shahzad, N: New fixed point theorem under R-contractions. Fixed Point Theory Appl. 2015, 98 (2015)

8. Abkar, A, Gabeleh, M: Best proximity points for cyclic mappings in ordered metric spaces. J. Optim. Theory Appl. 150(1), 188-193 (2011)

9. Basha, SS: Discrete optimization in partially ordered sets. J. Glob. Optim. 54(3), 511-517 (2012)

10. Bilgili, N, Karapinar, E, Sadarangani, K: A generalization for the best proximity point of Geraghty-contractions. J. Inequal. Appl. 2013, 286 (2013)

11. de la Sen, M, Agarwal, RP: Some fixed point-type results for a class of extended cyclic self-mappings with a more general contractive condition. Fixed Point Theory Appl. 2011, 59 (2011)

12. Eldred, AA, Veeramani, P: Existence and convergence of best proximity points. J. Math. Anal. Appl. 323(2), 1001-1006 (2006)

13. Jleli, M, Karapinar, E, Samet, B: A best proximity point result in modular spaces with the Fatou property. Abstr. Appl. Anal. 2013, Article ID 329451 (2013) 
14. Jeli, M, Karapinar, E, Samet, B: A short note on the equivalence between best proximity points and fixed point results. J. Inequal. Appl. 2014, 246 (2014)

15. Jleli, M, Samet, B: An optimization problem involving proximal quasi-contraction mappings. Fixed Point Theory Appl. 2014, 141 (2014)

16. Karapinar, E: Fixed point theory for cyclic weak $\phi$-contraction. Appl. Math. Lett. 24(6), 822-825 (2011)

17. Karapinar, E, Pragadeeswarar, V, Marudai, M: Best proximity point for generalized proximal weak contractions in complete metric space. J. Appl. Math. 2014, Article ID 150941 (2014)

18. Kim, WK, Lee, KH: Existence of best proximity pairs and equilibrium pairs. J. Math. Anal. Appl. 316(2), $433-446$ (2006)

19. Kirk, WA, Reich, S, Veeramani, P: Proximinal retracts and best proximity pair theorems. Numer. Funct. Anal. Optim. 24(7-8), 851-862 (2003)

20. Nashine, HK, Kumam, P, Vetro, C: Best proximity point theorems for rational proximal contractions. Fixed Point Theory Appl. 2013, 95 (2013)

21. Raj, VS: A best proximity point theorem for weakly contractive non-self-mappings. Nonlinear Anal. 74(14), 4804-4808 (2011)

22. Srinivasan, PS, Veeramani, P: On existence of equilibrium pair for constrained generalized games. Fixed Point Theory Appl. 2004(1), 21-29 (2004)

23. Pragadeeswarar, V, Marudai, M: Best proximity points for generalized proximal weak contractions satisfying rational expression on ordered metric spaces. Abstr. Appl. Anal. 2015, Article ID 361657 (2015)

\section{Submit your manuscript to a SpringerOpen ${ }^{\ominus}$ journal and benefit from:}

- Convenient online submission

Rigorous peer review

- Immediate publication on acceptance

- Open access: articles freely available online

- High visibility within the field

- Retaining the copyright to your article 